\title{
Prevalence of vitamin D deficiency in antenatal women
}

\author{
Anu Bala Chandel ${ }^{1 *}$, Rita Mittal ${ }^{1}$, Anoop Sharma ${ }^{1}$, Shivika Mittal' ${ }^{2}$, Poonam Samyal ${ }^{1}$
}

\begin{abstract}
${ }^{1}$ Department of Obstetrics and Gynecology, Kamla Nehru Hospital, Shimla, Himachal Pradesh, India
${ }^{2}$ Department of Obstetrics and Gynecology, RPGMC, Tanda, Kangra, Himachal Pradesh, India
\end{abstract}

Received: 17 March 2019

Accepted: 04 April 2019

\section{*Correspondence:}

Dr. Anu Bala Chandel,

E-mail: anuchande107@gmail.com

Copyright: (c) the author(s), publisher and licensee Medip Academy. This is an open-access article distributed under the terms of the Creative Commons Attribution Non-Commercial License, which permits unrestricted non-commercial use, distribution, and reproduction in any medium, provided the original work is properly cited.

\begin{abstract}
Background: Vitamin D has an increasingly recognised repertoire of non-classical actions, such as promoting insulin action and secretion, immune modulation and lung development. It therefore has the potential to influence many factors in the developing fetus. Several studies reported the relationship between maternal vitamin D deficiency and adverse maternal and fetal outcomes including gestational diabetes, preeclampsia, preterm labour, low birth weight and increased rate of caesarean section. The present study was undertaken to study the prevalence of vitamin D deficiency in antenatal women of Shimla, India.

Methods: The study was conducted in the department of Obstetrics and Gynaecology, Kamla Nehru Hospital, Shimla, India over a period of 12 months. Six hundred women were included in the study.

Results: Out of 600 subjects, $568(94.67 \%)$ subjects had vitamin D deficiency and only $32(5.33 \%)$ subjects had sufficient vitamin D levels. Vitamin D deficiency was more common in the vegetarians, dark skinned subjects and in those who were taking vitamin D supplements.

Conclusions: It is concluded from this study that there is high prevalence of vitamin D deficiency in antenatal women of Shimla, India.
\end{abstract}

Keywords: Caesarean section, Preeclampsia, Vitamin D deficiency

\section{INTRODUCTION}

Vitamin D has an increasingly recognised repertoire of non-classical actions, such as promoting insulin action and secretion, immune modulation and lung development. It therefore has the potential to influence many factors in the developing fetus. ${ }^{1}$

At no other time during the life cycle, is vitamin D status more important than during pregnancy, as mother is the sole source of vitamin D substrate for her developing fetus. $^{2}$ Vitamin D is a fat soluble vitamin produced endogenously in the skin with exposure to sunlight. It is also obtained from consuming fortified milk or juice, fish oils and dietary supplements of vitamin D. ${ }^{3}$
Several modifications of vitamin D metabolism occur during pregnancy. The expression of 1 alpha hydroxylase is increased in kidney and placenta and the concentration of serum 1, 25-dihydroxyvitamin D increases in normal pregnancy. By 12 weeks of gestation 1, $25(\mathrm{OH})$ D levels are more than twice that of non pregnant adult. The levels of vitamin D continues to rise two to threefold from the non pregnant baseline, attaining levels that would be toxic due to hypercalcemia to the nonpregnant adult, but they are essential during pregnancy. ${ }^{4}$

The largest source of vitamin D in adults is synthesis from solar radiation; half an hour of sunlight delivers 50000 IU of vitamin D with white-complexioned skin. Dietary intake of vitamin D makes a relatively small 
contribution to overall vitamin D status as there is little vitamin D that occurs naturally in the food supply. Melanin absorbs ultraviolet B (UVB) from sunlight and diminishes cholecalciferol production by at least $90 \%$. Dietary vitamin D is absorbed from the intestine and circulates in plasma bound to a vitamin $\mathrm{D}$ binding protein. ${ }^{1}$

Several studies reported the relationship between maternal vitamin D deficiency and adverse maternal and fetal outcomes including gestational diabetes, preeclampsia, preterm labour, low birth weight and increased rate of caesarean section. ${ }^{5}$ Several studies have reported increased frequency of emergency caesarean delivery in relation to low vitamin D levels. ${ }^{6}$

The prevalence of vitamin D deficiency has increased and continues to be a major public health problem in many countries. High prevalence of vitamin D deficiency has been observed among pregnant women even in sun rich areas. ${ }^{4}$ Vitamin D levels are influenced by many factors such as skin pigmentation, use of sunscreens, ethnicity, dress code, geographic latitude, seasonal variation and use of prenatal vitamin. ${ }^{5}$ This study was undertaken to study the prevalence of vitamin D deficiency in antenatal women.

\section{METHODS}

Observational study conducted in the Department of Obstetrics and Gynecology, Kamla Nehru State Hospital for Mother and child, IGMC, Shimla, India w.e.f. $1^{\text {st }}$ August 2017 to $31^{\text {st }}$ July 2018.

All women fulfilling the inclusion criteria were included in the study.

\section{Inclusion criteria}

- $\quad$ Age 18-40 years

- Primigravida

- Confirmed viable singleton intrauterine pregnancy

- $\quad$ POG more than or equal to 28 weeks

\section{Exclusion criteria}

- Current or past medical illness which may interfere with vitamin D and calcium levels such as hyperparathyroidism, collagen diseases, cushing's disease, chronic renal disease, GI disease, lung cancer and ovarian tumours

- $\quad$ Taking medications that interfere with vitamin D and calcium

- levels-anticonvulsants, corticosteroids, thiazides, thyroxine, heparin, antitubercular drugs

- Known case of diabetes, hypertension

- Multiple pregnancy

- Multiparity.
About 600 women fulfilling the inclusion criteria at POG $>=28$ weeks of pregnancy and delivering in labour room of our hospital were included after written informed consent. Information on age, education, occupation, income, religion, diet, vitamin supplements and dairy products intake, exposure to sunlight etc. was obtained from the subjects using a questionnaire.

A fasting blood sample of minimum $2 \mathrm{ml}$ was taken and was tested for serum 25(OH)D by CMIA (chemiluminescent microparticle immunoassay) method in hospital lab. LC-MS/MS (liquid chromatography-mass spectrometry) procedure was used for vitamin D quantification.

The patients were categorised as per the levels:

- Severe deficiency - $<10 \mathrm{ng} / \mathrm{ml}$

- Moderate deficiency- 10- $19.9 \mathrm{ng} / \mathrm{ml}$

- $\quad$ Mild deficiency- 20-29.9 ng/ml

- Optimal level >=30 ng/ml

\section{Statistical analysis}

All the data was entered in Microsoft Excel 2007 spreadsheet. Categorical variables were analysed using Chi square and Fischer exact test. Continuous variables were analysed using the appropriate tests after checking for the normality distribution using Kolmogrov Smirnoff test.

- $\quad(\mathrm{S})=$ Significant

- $\quad(\mathrm{NS})=$ Not Significant

A P-value of 0.05 or less was considered statistically significant.

\section{RESULTS}

Out of 600 subjects, $32(5.33 \%)$ subjects had sufficient vitamin D levels and $568(94.67 \%)$ had vitamin D deficiency. Among the vitamin D deficient subjects, 46 (7.66\%) had mild, 159 (26.50\%) had moderate and 363 $(60.50 \%)$ had severe vitamin D deficiency (Table 1$)$.

Table 1: Distribution of subjects according to vitamin D status.

\begin{tabular}{|ll|}
\hline Vitamin D levels & Number of patients \\
\hline Sufficient levels & $32(5.33 \%)$ \\
\hline Mild deficiency & $46(7.66 \%)$ \\
\hline Moderate deficiency & $159(26.50 \%)$ \\
\hline Severe deficiency & $363(60.50 \%)$ \\
\hline
\end{tabular}

Majority of the vitamin deficient subjects were unbooked $(95.52 \%)$, <30 years old $(95 \%)$, obese $(98.19 \%)$, belonging to urban areas $(97.20 \%)$, less than secondary educated (96.43\%),working women (95.69\%), upper socioeconomic status (96.95\%), Muslims (97.06\%), 
vegetarians $(96.99 \%)$, dark skinned $(98.07 \%)$, in winters $(98.51 \%)$, less exposed to sun $(99.62 \%)$, not consuming dairy products $(99.08 \%)$ and vitamin supplements $(98.07 \%)$.

Table 2: Demographic factors.

\begin{tabular}{|c|c|c|c|c|}
\hline Variables & Total $(n=600)$ & Vitamin D deficient $(\mathrm{n}=568)$ & Vitamin D sufficient $(\mathrm{n}=32)$ & P Value \\
\hline Booked & $88.83 \%$ & $504(94.56 \%)$ & $29(5.44 \%)$ & \multirow{2}{*}{0.966 (NS) } \\
\hline Unbooked & $11.17 \%$ & $64(95.52 \%)$ & $3(4.48 \%)$ & \\
\hline Age $<=30$ years & $76.67 \%$ & $437(95 \%)$ & $23(5 \%)$ & \multirow{2}{*}{$0.65(\mathrm{NS})$} \\
\hline Age $>30$ years & $23.33 \%$ & $131(93.57 \%)$ & $9(6.43 \%)$ & \\
\hline \multicolumn{5}{|l|}{ BMI } \\
\hline$<18.5 \mathrm{Kg} / \mathrm{m}^{2}$ & $11 \%$ & $63(95.46 \%)$ & $3(4.54 \%)$ & \multirow{4}{*}{$0.127(\mathrm{NS})$} \\
\hline $18.5-24.9 \mathrm{Kg} / \mathrm{m}^{2}$ & $57.33 \%$ & $321(93.32 \%)$ & $23(6.68 \%)$ & \\
\hline $25-29.9 \mathrm{Kg} / \mathrm{m}^{2}$ & $13.33 \%$ & $76(95 \%)$ & $4(5 \%)$ & \\
\hline$>=30 \mathrm{Kg} / \mathrm{m}^{2}$ & $18.34 \%$ & $108(98.19 \%)$ & $2(1.81 \%)$ & \\
\hline Rural & $58.33 \%$ & $325(92.86 \%)$ & $25(7.14 \%)$ & \multirow{2}{*}{$0.03(\mathrm{~S})$} \\
\hline Urban & $41.67 \%$ & $242(97.20 \%)$ & $7(2.80 \%)$ & \\
\hline \multicolumn{5}{|l|}{ Education } \\
\hline$<=$ Secondary & $46.66 \%$ & $270(96.43 \%)$ & $10(3.57 \%)$ & \multirow{2}{*}{$0.106(\mathrm{NS})$} \\
\hline$>$ Secondary & $53.34 \%$ & $298(93.13 \%)$ & $22(6.87 \%)$ & \\
\hline House Wife & $69 \%$ & $390(94.20 \%)$ & $24(5.80 \%)$ & \multirow{2}{*}{$0.57(\mathrm{NS})$} \\
\hline Working & $31 \%$ & $178(95.69 \%)$ & $8(4.31 \%)$ & \\
\hline Upper class & $21.83 \%$ & $127(96.95 \%)$ & $4(3.05 \%)$ & \multirow{3}{*}{$0.614(\mathrm{NS})$} \\
\hline Middle class & $58 \%$ & $356(94.18 \%)$ & $22(5.82 \%)$ & \\
\hline Lower class & $15.17 \%$ & $85(93.14 \%)$ & $6(6.59 \%)$ & \\
\hline Hindu & $91.83 \%$ & $523(94.92 \%)$ & $28(5.08 \%)$ & \multirow{3}{*}{$0.55(\mathrm{NS})$} \\
\hline Muslim & $5.67 \%$ & $33(97.06 \%)$ & $1(2.94 \%)$ & \\
\hline Sikh & $2.50 \%$ & $12(80 \%)$ & $3(20 \%)$ & \\
\hline Vegetarian & $55.50 \%$ & $323(96.99 \%)$ & $10(3.01 \%)$ & \multirow{2}{*}{$0.007(\mathrm{~S})$} \\
\hline Non vegetarian & $44.50 \%$ & $245(91.76 \%)$ & $22(8.24 \%)$ & \\
\hline Summer & $66.33 \%$ & $369(92.70 \%)$ & $29(7.29 \%)$ & \multirow{2}{*}{$0.005(\mathrm{~S})$} \\
\hline Winter & $33.67 \%$ & $199(98.51 \%)$ & $3(1.49 \%)$ & \\
\hline \multicolumn{5}{|c|}{ Exposure to sunlight } \\
\hline More & $13 \%$ & $48(61.54 \%)$ & $30(38.46 \%)$ & \\
\hline Less & $87 \%$ & $520(99.62 \%)$ & $2(0.38 \%)$ & $0.00(\mathrm{~S})$ \\
\hline \multicolumn{5}{|l|}{ Supplements } \\
\hline Yes & $13.50 \%$ & $59(72.84 \%)$ & $22(27.16 \%)$ & \multirow{2}{*}{$0.00(\mathrm{~S})$} \\
\hline No & $86.50 \%$ & $509(98.07 \%)$ & $10(1.93 \%)$ & \\
\hline \multicolumn{5}{|l|}{ Dairy products } \\
\hline Yes & $27.50 \%$ & $137(83.03 \%)$ & $28(16.97 \%)$ & \multirow{2}{*}{$0.00(\mathrm{~S})$} \\
\hline No & $72.50 \%$ & $431(99.08 \%)$ & $4(0.92 \%)$ & \\
\hline \multicolumn{5}{|l|}{ Skin } \\
\hline Fair & $48.17 \%$ & $263(91.01 \%)$ & $26(8.99 \%)$ & \multirow{2}{*}{$0.00(\mathrm{~S})$} \\
\hline Dark & $51.83 \%$ & $305(98.07 \%)$ & $6(1.93 \%)$ & \\
\hline
\end{tabular}

\section{DISCUSSION}

Vegetarian diet, no intake of vitamin supplements and dairy products, dark skin and less exposure to sunlight contributes to vitamin D deficiency. Our study shows statistically significant association of vitamin D deficiency in urban population, vegetarian diet, dark skinned subjects, having less exposure to sunlight, no supplements of vitamin D and no intake of dairy products.

In this study, only $5.33 \%$ subjects had sufficient vitamin D levels while $94.67 \%$ subjects had vitamin D deficiency which was comparable to the studies conducted by Kumari V et al, Pahuja N et al and Prasad D et al..$^{3,7,8}$ 
As per this study, vitamin D deficiency was there in $98.19 \%$ of the obese subjects which was comparable to the study conducted by Gupta $\mathrm{M}$ et al, i.e. $100 \% .^{10}$ Sequestration of vitamin $\mathrm{D}$ in the fat tissue is responsible for low serum vitamin D levels in the obese subjects.

In present study vitamin $\mathrm{D}$ deficiency was more in subjects belonging to urban as compared to rural area i.e. $97.20 \%$ and $92.86 \%$ respectively, which was similar from the study conducted by Prasad D et al, i.e. $95.52 \%$ vs. $72.73 \% .^{8}$ Increasing urbanisation that results in poor outdoor activities, greater pollution coupled with dark skin complexion may be the contributory factors for more vitamin D deficiency in urban areas.

In present study vitamin D deficiency was comparable in both housewives and working group i.e. $94.20 \%$ vs. $95.69 \%$ which was similar to the study conducted by Prasad D et al. ${ }^{8}$ Restriction of outdoor activities and confinement at home may be the contributory factor to more vitamin D deficiency in housewives.

Vitamin D deficiency was more in the Muslim group $(97.06 \%)$ in the present study which was similar to the study results given by Pahuja $\mathrm{N}$ et al 7 (100\%). The tradition of burkha system among the Muslims contributes to vitamin D deficiency in this group. Severe vitamin D deficiency was significantly higher in subjects who were sampled in winters compared to those who were sampled in summers i.e. $84.16 \%$ vs. $48.49 \%$ which was similar to the study conducted by Ates $\mathrm{S}$ et al, $(61.21 \%$ vs. $29.73 \%) .^{5}$ Vitamin D deficiency was significantly higher in subjects who were less exposed to the sunlight $(99.62 \%)$. Similar results were there in the study conducted by Dave A et al, and Prasad D et al. ${ }^{8,9}$ Adequate exposure to the sunlight is essential for vitamin $\mathrm{D}$ production in our body and is markedly decreased in winters.

Vitamin D levels were lower in subjects who were not taking vitamin supplements $(98.07 \%)$ and not consuming dairy products $(99.08 \%)$.

In our study $98.07 \%$ dark skinned subjects were vitamin $\mathrm{D}$ deficient which was similar to results by Pahuja $\mathrm{N}$ et al. ${ }^{7}$ Melanin in the dark skin hampers the production of vitamin D.

\section{CONCLUSION}

It is concluded form this study that there is high prevalence of vitamin D deficiency in pregnancy. In our study, we found that women from all ages, socioeconomic status, irrespective of education levels had inadequate vitamin D levels. Hence we recommend routine screening of antenatal women for vitamin D levels and increase supplementation or exposure to sunlight in all pregnant women to keep serum levels of vitamin $\mathrm{D}$ in the normal range for adults.

Funding: No funding sources

Conflict of interest: None declared

Ethical approval: The study was approved by the Institutional Ethics Committee

\section{REFERENCES}

1. Royal College of Obstetricians and Gynaecologists. Vitamin D in Pregnancy. Scientific Impact Paper No 43. London: RCOG; 2014.

2. Singh N, Kumar D, Singh J, Chandanan A. A study of Vitamin D, Its supplementation and effect on fetomaternal outcome during pregnancy. Indian $\mathbf{J}$ Res. 2015;4(9):270-2.

3. Vasundhara K, Swapna R, Prasannalatha A, Shruti K. Vitamin D Supplementation in pregnancy and its correlation with fetomaternal outcome. Ann Nutr Disord Ther. 2017;4(1):1037:1-5.

4. Sharma S, Kumar A, Prasad S, Sharma S. Current scenario of vitamin D status during pregnancy in north Indian population. J Obstet Gynaecol India. 2016;66(2):93-100.

5. Ates S, Sevket O, Ozcan P, Ozkal F, Kaya MO, Dane B. Vitamin D status in the first trimester: effects of Vitamin D deficiency on pregnancy outcomes. Afri Health Sci. 2016;16(1):36-43.

6. Lindqvist PG, Silva AT, Gustafsson SA, Gidlof Sebastian. Maternal vitamin D deficiency and fetal distress/birth asphyxia:a population based nested case-control study. BMJ Open. 2016;6:e009733.

7. Pahuja N, Chauhan N, Kalra V. Vitamin D levels in pregnant women in Uttarakhand, India. Int J Reprod Contracept Obstet Gynecol. 2018;7(1):169-72.

8. Prasad D, Smita, Singh K, Nisha S. Vitamin D in pregnancy and its correlation with feto maternal outcome. Int J Contemp Med Res. 2018;5(1):1-5.

9. Dave A, Verma AM, Jain N, Dave A. A study of vitamin D levels and associated deficiency in pregnancy and its effect on maternal and fetal outcome. Int J Reprod Contracep Obstet Gynecol. 2017;6(1):84-8.

10. Gupta M, Debnath A, Jain S, Saini V, Ray S. Vitamin D status in pregnancy: fetomaternal outcome and correlation with cord blood vitamin D. Indian J Med Biochem. 2017;21(1):42-8.

Cite this article as: Chandel $\mathrm{AB}$, Mittal R, Sharma A, Mittal S, Samyal P. Prevalence of vitamin D deficiency in antenatal women. Int J Reprod Contracept Obstet Gynecol 2019;8:2302-5. 